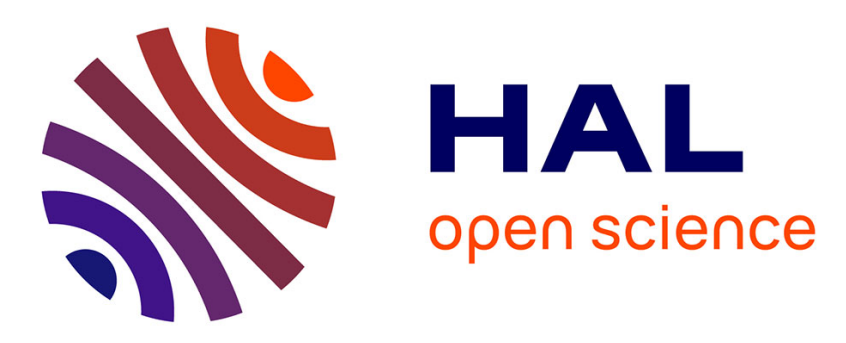

\title{
Dielectric strength of parylene HT
}

Sombel Diaham, Mireille Bechara-Keyrouz, Marie-Laure Locatelli, Rabih Khazaka, Christophe Tenailleau, Rakesh Kumar

\section{To cite this version:}

Sombel Diaham, Mireille Bechara-Keyrouz, Marie-Laure Locatelli, Rabih Khazaka, Christophe Tenailleau, et al.. Dielectric strength of parylene HT. Journal of Applied Physics, 2014, vol. $115\left(\mathrm{n}^{\circ} 5\right)$, pp.054102. 10.1063/1.4863877 . hal-01163374

\section{HAL Id: hal-01163374 https://hal.science/hal-01163374}

Submitted on 12 Jun 2015

HAL is a multi-disciplinary open access archive for the deposit and dissemination of scientific research documents, whether they are published or not. The documents may come from teaching and research institutions in France or abroad, or from public or private research centers.
L'archive ouverte pluridisciplinaire HAL, est destinée au dépôt et à la diffusion de documents scientifiques de niveau recherche, publiés ou non, émanant des établissements d'enseignement et de recherche français ou étrangers, des laboratoires publics ou privés. 


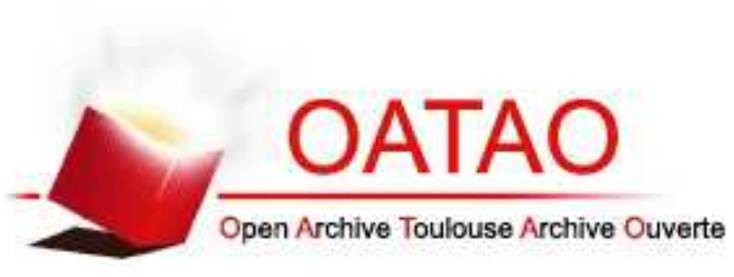

\section{Open Archive TOULOUSE Archive Ouverte (OATAO)}

OATAO is an open access repository that collects the work of Toulouse researchers and makes it freely available over the web where possible.

This is an author-deposited version published in : http://oatao.univ-toulouse.fr/ Eprints ID : 13966

To link to this article : DOI:10.1063/1.4863877

URL : http://dx.doi.org/10.1063/1.4863877

\section{To cite this version :}

Diaham, Sombel and Bechara, Mireille and Locatelli, Marie-Laure and Khazaka, Rabih and Tenailleau, Christophe and Kumar, Rakesh Dielectric strength of parylene HT. (2014) Journal of Applied Physics, vol. 115 ( ${ }^{\circ}$ 5). 054102. ISSN 0021-8979

Any correspondance concerning this service should be sent to the repository administrator: staff-oatao@listes-diff.inp-toulouse.fr 


\title{
Dielectric strength of parylene HT
}

\author{
S. Diaham, ${ }^{1,2, a)}$ M. Bechara, ${ }^{1,2}$ M.-L. Locatelli, ${ }^{1,2}$ R. Khazaka, ${ }^{1,2}$ C. Tenailleau, ${ }^{3}$ \\ and R. Kumar ${ }^{4}$ \\ ${ }^{1}$ Université de Toulouse, UPS, INPT, LAPLACE, 118 route de Narbonne-Bât. 3R3, F-31062 Toulouse Cedex 9 , \\ France \\ ${ }^{2}$ CNRS, LAPLACE, F-31062 Toulouse, France \\ ${ }^{3}$ Université de Toulouse, UPS, Laboratoire CIRIMAT/LCMIE, 118 route de Narbonne-Bât. $2 R 1$, \\ F-31062 Toulouse Cedex 9, France \\ ${ }^{4}$ Speciality Coating Systems, Inc. (SCS), Cookson Electronics, 7645 Woodland Drive, Indianapolis, \\ Indiana 46278, USA
}

\begin{abstract}
The dielectric strength of parylene HT (PA-HT) films was studied at room temperature in a wide thickness range from $500 \mathrm{~nm}$ to $50 \mu \mathrm{m}$ and was correlated with nano- and microstructure analyses. X-ray diffraction and polarized optical microscopy have revealed an enhancement of crystallization and spherulites development, respectively, with increasing the material thickness $(d)$. Moreover, a critical thickness $d_{C}$ (between 5 and $10 \mu \mathrm{m}$ ) is identified corresponding to the beginning of spherulite developments in the films. Two distinct behaviors of the dielectric strength $\left(F_{B}\right)$ appear in the thickness range. For $d \geq d_{C}$, PA-HT films exhibit a decrease in the breakdown field following a negative slope $\left(F_{B} \sim d^{-0.4}\right)$, while for $d<d_{C}$, it increases with increasing the thickness $\left(F_{B} \sim d^{0.3}\right)$. An optimal thickness $d_{\text {optim }} \sim 5 \mu \mathrm{m}$ corresponding to a maximum dielectric strength $\left(F_{B} \sim 10 \mathrm{MV} / \mathrm{cm}\right)$ is obtained. A model of spherulite development in PA-HT films with increasing the thickness is proposed. The decrease in $F_{B}$ above $d_{C}$ is explained by the spherulites development, whereas its increase below $d_{C}$ is induced by the crystallites growth. An annealing of the material shows both an enhancement of $F_{B}$ and an increase of the crystallites and spherulites dimensions, whatever the thickness. The breakdown field becomes thickness-independent below $d_{C}$ showing a strong influence of the nano-scale structural parameters. On the contrary, both nano- and micro-scale structural parameters appear as influent on $F_{B}$ for $d \geq d_{C}$.

http://dx.doi.org/10.1063/1.4863877
\end{abstract}

\section{INTRODUCTION}

Parylene HT (PA-HT), a commercial grade of fluorinated parylene AF4 polymer, ${ }^{1}$ is a recent thermo-stable semicrystalline polymer that appears as a suitable solution for the electrical insulation of high temperature power electronics, MEMS packaging, sensor or fuel cell protection, where a high degree of surface conformation is required. ${ }^{2}$ PA-HT is coated at the molecular level using a vapor deposition polymerization (VDP) process allowing the deposition of conformal submicron and micron layers (from $100 \mathrm{~nm}$ to $50 \mu \mathrm{m}$ ) with high purity. ${ }^{1,3}$ However, it is expected that PA-HT physical properties in such a wide range of thicknesses should deviate between thin layers and thick films.

Since the beginning of the 2000s, more and more efforts have been dedicated in the study of the thickness dependence of the molecular dynamics in thin polymers. Some of these studies deal with the thickness influence on the glass transition dynamics for amorphous materials, ${ }^{4,5}$ while others carry out the effect on the crystal and spherulite growth in semicrystalline ones. ${ }^{6-9}$ For semicrystalline thin-films, most of the studies correlate X-rays measurements and optical microscopy with dielectric spectroscopy measurements.

\footnotetext{
a) Author to whom correspondence should be addressed. Electronic mail: sombel.diaham@laplace.univ-tlse.fr.
}

However, little is known regarding the influence of the thickness and the crystallization on the dielectric strength, and the physical interpretations are not clear yet. Up to now, Kim and Shi have carried out the thickness dependence of the dielectric breakdown field for poly(tetrafluoroethylene) (PTFE) thin-films $(\leq 1141 \mathrm{~nm}){ }^{10}$ They found that the crystallinity and the crystallite size increase with increasing PTFE film thickness. However, they simultaneously observed a reduction in the dielectric strength and attempted to explain such a result with an electromechanical breakdown origin. Earlier, Kitagawa et al. showed that the dielectric strength of thin polyethylene (PE) films $(\leq 1400 \mathrm{~nm})$ falls down when increasing thickness. ${ }^{11}$ The origin of the breakdown was related to the spherulite boundaries wherein electronic avalanche could develop easily through longer mean free paths.

However, the increase in crystallinity through crystallite growth should lead theoretically to higher values in the breakdown field and to lower values in the electrical conductivity due to higher difficulties for free charges to move into an ordered polymeric structure. Therefore, this should shift the occurrence of the thermal runaway or the electronic avalanche towards higher electric fields. For instance, Amborski has carried out that crystallization results in the conductivity decrease in poly(ethylene terephthalate), ${ }^{12}$ while Ikezaki et al. reported both a charge injection limitation at the 
interfaces and a hopping jump distance reduction (i.e., increase in the trap density) in the bulk when polypropylene crystallinity rises. $^{13}$

In previous papers, we reported the influence of a thermal annealing of PA-HT leading to a strong reduction of the charge carrier mobility and/or density ${ }^{14}$ and of the dynamics of the local and segmental chain motions in the amorphous phase. ${ }^{15}$ These studies highlighted that crystallization plays an important role on the electrical and dielectric properties of PA-HT, making possible an optimization of the macromolecular structure to get the better insulating properties for application issues.

The present paper tries to carry out a better understanding of the links existing between the crystallization development with the thickness $(d)$ and its effects on the dielectric strength $\left(F_{B}\right)$ using similar PA-HT films. Results reveal the existence of a critical thickness $\left(d_{C}\right)$ in PA-HT, corresponding to the beginning of spherulite development in the layer. Slightly below $d_{C}$, the dielectric strength reaches its maximum value for an optimal thickness $\left(d_{\text {optim }}\right)$. For thicknesses $d \ll d_{C}$ and $d \gg d_{C}$, a decrease in the dielectric strength is observed related to crystallization reduction and spherulite multiplication, respectively.

\section{EXPERIMENTAL PART}

PA-HT films were coated at room temperature onto mirror-polished stainless steel substrates $\left(3.3 \times 3.3 \mathrm{~cm}^{2}\right)$ by VDP using the Gorham process at Speciality Coating Systems, Inc. (SCS) (see Fig. 1). Before the coating, substrates were treated using an adhesion promoter (AdPro Plus ${ }^{\circledR}$, SCS). Different thicknesses were prepared in the range from $500 \mathrm{~nm}$ up to $50 \mu \mathrm{m}$ (i.e., 0.5, 1.4, 4.8, 9.8, 21.5, and $49.4 \mu \mathrm{m}$ ). Thicknesses were accurately measured (several times at different positions of each coating) with a KLA Tencor Alpha-A mechanical profilometer (accuracy in $z$-direction $\pm 0.01 \mu \mathrm{m})$. Surface roughness was measured with a Veeco NT3300 optical profilometer in vertical scanning interferometry mode (accuracy in $z$-direction $\pm 3 \mathrm{~nm}$ ).

Nano- and microstructural analysis was performed by X-ray diffraction (XRD) using a D5000 Bruker diffractometer with a $\mathrm{CuK}_{\alpha}$ radiation $(\lambda=1.5418 \AA)$ and a $1^{\circ}$-grazing incidence angle over $10^{\circ}$ to $80^{\circ}$ in $2 \theta\left(0.02^{\circ}\right.$ step size and $10 \mathrm{~s} / \mathrm{step}$ scans). Finally, the spherulites development was observed using a laser scanning confocal optical microscope (Olympus LEXT) with a white polarized-light.

Dielectric strength measurements were performed in DC using a plan-plan electrode configuration. The stainless steel substrates used for the PA-HT coatings were connected to

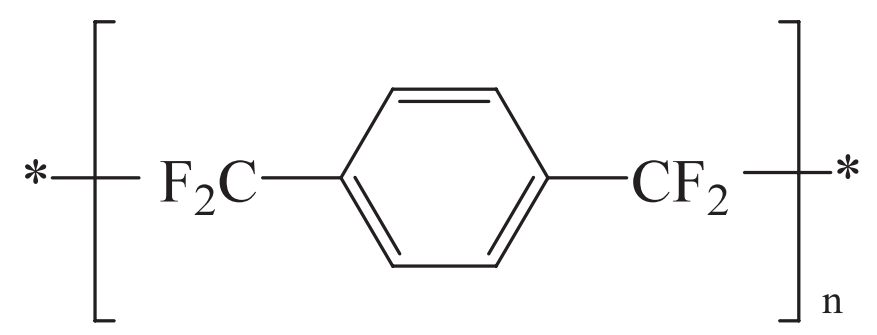

FIG. 1. Chemical structure of the PA-HT (AF4 family) monomeric unit. the ground while the high voltage (HV) was applied onto the films through a stainless steel Rogowski-shaped upper electrode of $600 \mu \mathrm{m}$ in diameter. Numerical modeling of the breakdown cell, using finite elements and considering the electrode shapes and material permittivity, showed that field reinforcements remain negligible in the whole PA-HT thickness range investigated in this study. The DC linear voltage was generated using both a $3.5 \mathrm{kV}$ FUG or a $30 \mathrm{kV}$ Brandenburg Alpha-II DC voltage sources with a constant field ramp of $400 \mathrm{kV} / \mathrm{cm} / \mathrm{s}$ whatever the sample thickness. In order to avoid PA-HT surface flashovers, the breakdown cell was filled with a fluorinated insulating liquid. The current limit of the DC voltage source was fixed at $1 \mathrm{~mA}$ for the detection of the breakdown event and the last applied voltage before the breakdown was recorded using a Fluke voltmeter (with peak-hold) connected to the source through a $\mathrm{HV}$ probe $(1: 1000)$. All the measurements were performed at $23{ }^{\circ} \mathrm{C}$. For data treatment, a statistical analysis was used based on 20 breakdown tests for each investigated thickness. A Weibull distribution law was applied to the data with a $90 \%$ confidence interval, as described previously. ${ }^{16}$ The breakdown field presented in the following corresponds to the scale parameter of the Weibull law.

\section{RESULTS AND DISCUSSION}

In order to understand and carry out physical interpretations to the dielectric strength tendencies, it appears as fundamental to understand the structural "fingerprint" of PA-HT at the nano- and micro-scale and its dependence with the film thickness.

Fig. 2 shows XRD measurements and crystallite size evolution for film thicknesses from $500 \mathrm{~nm}$ to $49.4 \mu \mathrm{m}$. For very thin layers, PA-HT presents a large main peak located around $19.2^{\circ}$ (see Fig. 2(a)), which indicates that the material is partially crystallized as soon as it is coated onto the substrate. This peak is characteristic of the triclinic unit cell identified previously in parylene AF4. ${ }^{17}$ Moreover, it is observed that the intensity of the peak increases with increasing the film thickness. This highlights an increase in the crystallinity as the film thickness increases. Similar observations have recently been reported in parylene $C^{18,19}$ and PTFE in similar thickness ranges. ${ }^{10}$ Due to the surface confinement induced by the substrates, molecular organization in thin polymer films is disturbed at low thickness. Consequently, the crystallization process can be easily retarded in thinnest films. When the thickness becomes sufficiently high, crystallization can be developed freely. The average crystallite size (D) can be obtained from Fig. 1(a) using the Scherrer formula $^{20}$

$$
D=\frac{0.9 \lambda}{B \cos \theta}
$$

where $\lambda$ is the wavelength of the incident $\mathrm{X}$-rays, $B$ is the full-width half maximum (FWHM), and $\theta$ is the angular position of the peak.

Fig. 2(b) shows that the crystallite $D$ size increases nonlinearly from 4.7 to $5.4 \mathrm{~nm}$ with increasing the film thickness from $500 \mathrm{~nm}$ up to $49.4 \mu \mathrm{m}$. Moreover, the crystallite size 

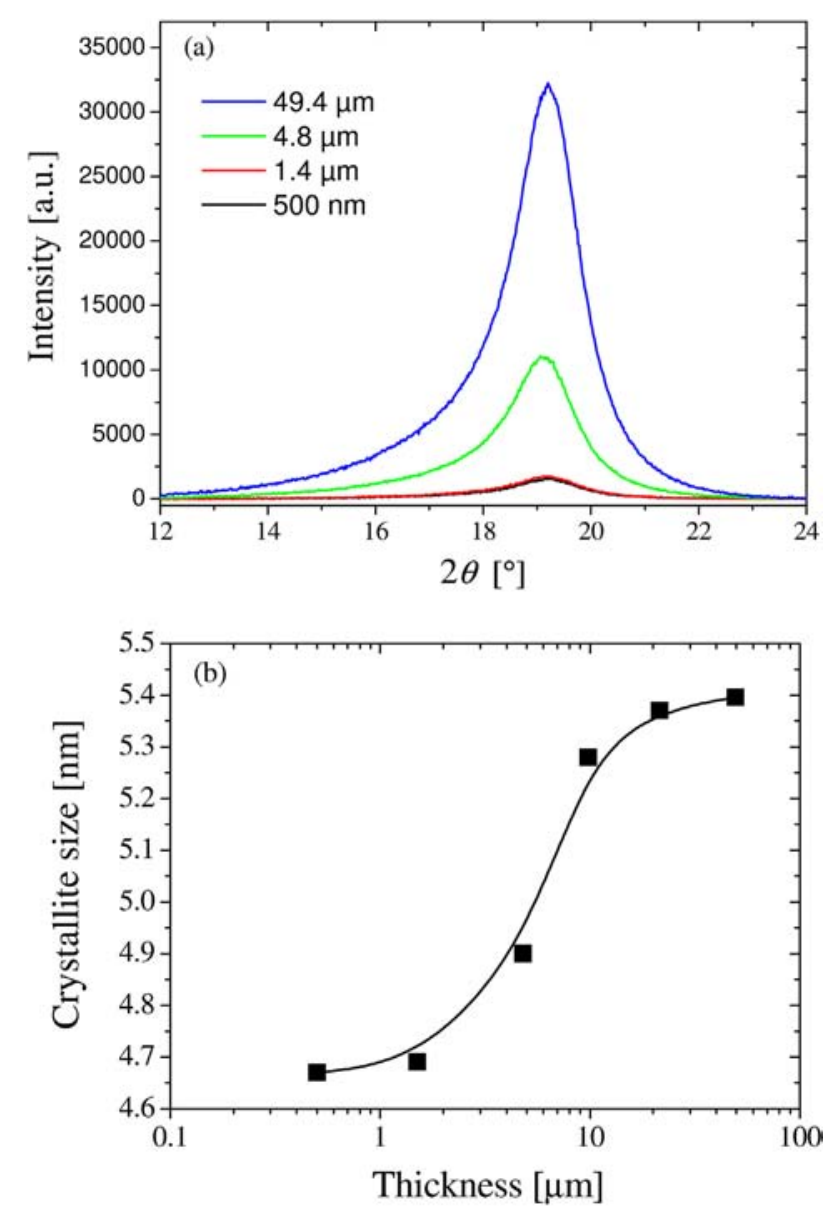

FIG. 2. XRD patterns of PA-HT for different film thicknesses (a) and crystallite size evolution versus film thickness (b).

shows a substantial increase for a threshold thickness around 2-3 $\mu \mathrm{m}$. Finally, $D$ reaches saturation above $10 \mu \mathrm{m}$. Thus, over this latter thickness, the continuous increase in the crystallinity is no more due to the increase in the crystallite size but probably due to another type of organization within the PA-HT microstructure. Recently, on the contrary, we reported that a high temperature annealing of $10 \mu \mathrm{m}$-thick PA-HT films allows an additional growing of the crystallites up to $7.8 \mathrm{~nm}$, associated to a decrease in the interlamellar spacing. It was observed that the additional crystallization process occurred preferentially by spherulite development of around $10 \mu \mathrm{m}$ in diameter. ${ }^{14,15}$

Usually, an increase in the crystallinity of a semicrystalline thin polymer is related to an increase in the surface roughness of the film. The influence of the PA-HT thickness on surface morphology has been studied by confocal optical microscopy, as shown in Fig. 3. The optical microscope images performed on 4.8 and $49.4 \mu \mathrm{m}$-thick films reveal a large difference in the PA-HT surface roughness. Indeed, the values of the roughness parameters $R_{a}$ and $R_{q}$ are 5 times lower for the $4.8 \mu \mathrm{m}$-thick films than those of the $49.4 \mu \mathrm{m}$ ones. Moreover, scattered grains appear clearly on the thickest films protruding from the film surface with a mean diameter around $5 \mu \mathrm{m}$. These kinds of grains only appear from a thickness of $10 \mu \mathrm{m}$ in a very low density and their amount strongly increases with PA-HT thickness. The nucleation of
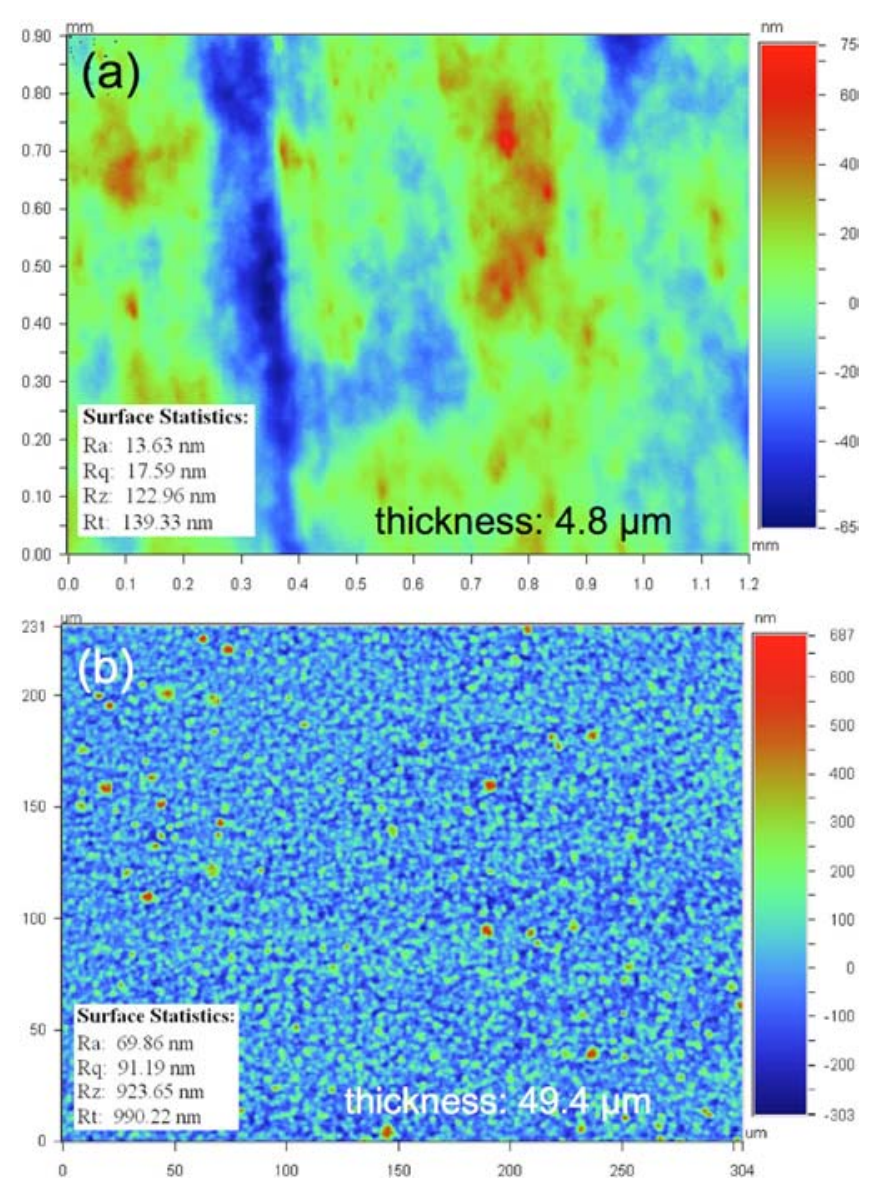

FIG. 3. Surface roughness of PA-HT for $4.8 \mu \mathrm{m}$ (a) and $49.4 \mu \mathrm{m}$ (b) film thicknesses.

such grains highlights microstructural changes when the PA-HT monomers are deposited during the VDP process. While over $10 \mu \mathrm{m}$ of thickness XRD did not reveal an increase in the crystallite size at the nano-scale, it seems that the further changes in the crystallization with increasing the film thickness is related to this grain nucleation at the micro-scale.

In order to deeply investigate the origin of such nucleated grains, optical microscopy has been performed in reflection mode versus film thickness $d$ (see Fig. 4). For thicknesses from $d \geq 9.8 \mu \mathrm{m}$, optical images reveal the presence of spherulites in PA-HT films. Spherulites consist in arrangement of dense lamellae stacks compound of both crystalline lamella and amorphous regions. ${ }^{21}$ The spherulites correspond to the scattered surfacic protruding grains observed before in Fig. 3. However, the polarized-light allows revealing contrasts among spherulites located at the surface with those in volume. A focusing in different planes of the films has shown a scattering of their position wherever in the PA-HT bulk. Furthermore, while no such spherulites are observed for lower thickness $(d<9.8 \mu \mathrm{m})$, their density increases with increasing the film thickness above $d \geq 9.8 \mu \mathrm{m}$, as obtained after a numerical image treatment (see Fig. 5). The mean diameter of the spherulites presents an increase from $3.2 \mu \mathrm{m}$ to $4.8 \mu \mathrm{m}$ when the film thickness increases from $9.8 \mu \mathrm{m}$ to $49.4 \mu \mathrm{m}$.

All these results highlight three main observations in PA-HT films. The first one validates the fact that the 

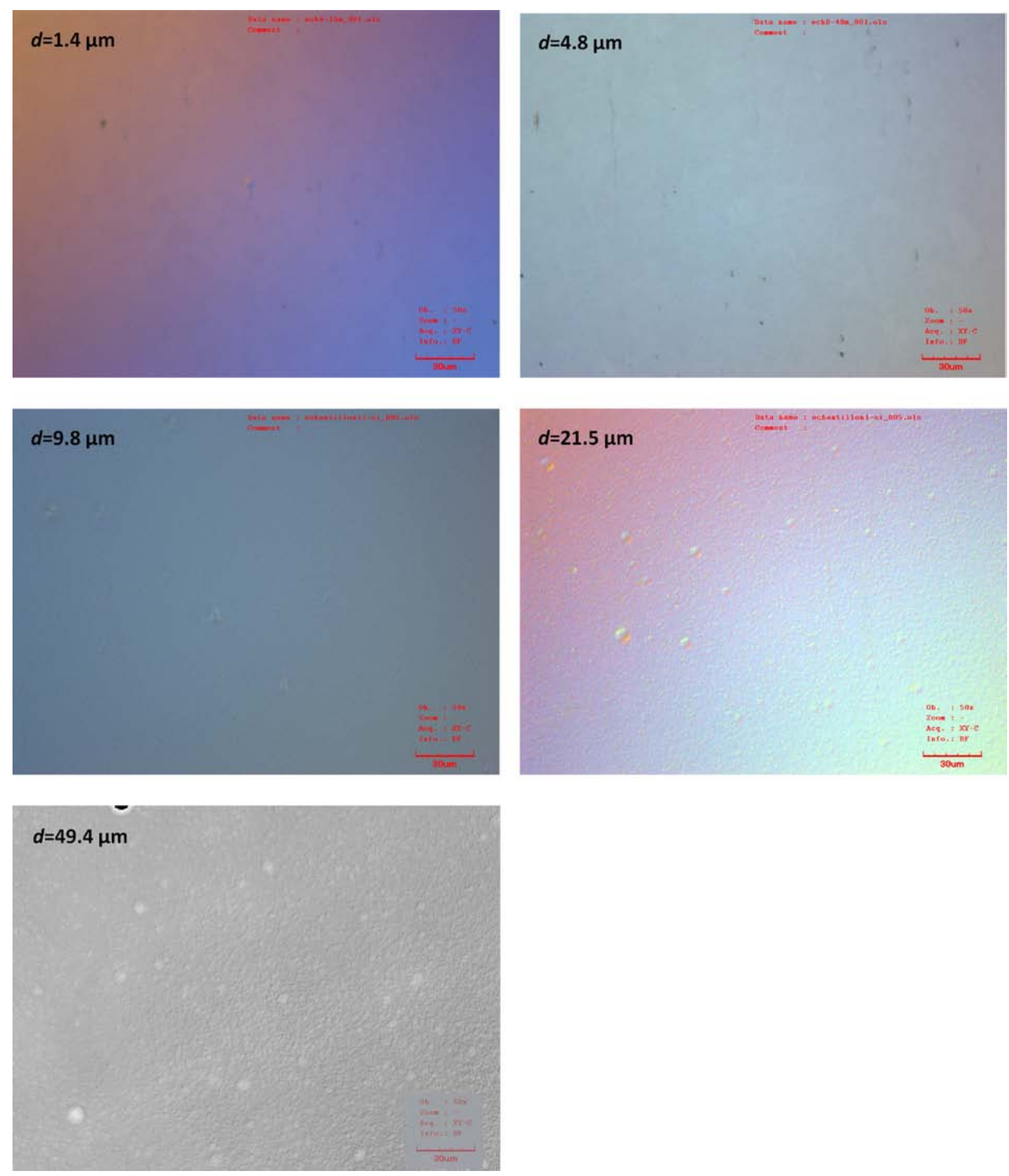

FIG. 4. Polarized optical microscope images of PA-HT for different thicknesses. The scale lines indicate a $30 \mu \mathrm{m}$-length.

crystallization increase with increasing thickness is progressively turned from a crystallite growing (nano-scale) into a spherulite development (micro-scale) in order to reach the thermodynamic equilibrium. The second one is that a critical (or minimum) thickness $\left(d_{C}\right)$ is required for the occurrence and full development of spherulites. Indeed, below $5 \mu \mathrm{m}$ of thickness, PA-HT does not exhibit the presence of such a microstructural organization. From $d>5 \mu \mathrm{m}$, the chains reorganize in order to form very low spherulite densities with weak diameter $(\sim 3 \mu \mathrm{m})$ before that they grow up with increasing PA-HT thickness. Consequently, the critical thickness $d_{C}$ for PA-HT is found between 5 and $10 \mu \mathrm{m}$. The last observation is the simultaneous strong multiplication and random growing of the spherulites within the PA-HT when the thickness is substantially higher than $d_{C}$. Such a proliferation is certainly induced in the vicinity of random nuclei. Most of the spherulites reach diameter of the same order with the critical thickness $d_{C}$, which is permitted by the reduction of the confinement (i.e., substrate distance and film thickness increase). This can explain why no such micro-scale structural organization was detected for $d<d_{C}$. 


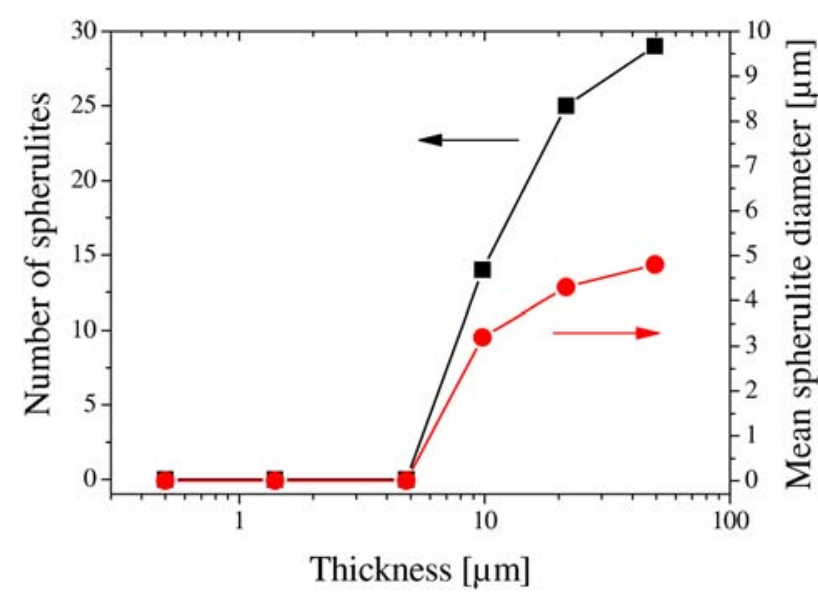

FIG. 5. Number and mean diameter of spherulites versus PA-HT thickness estimated from optical microscope images of $250 \times 187 \mu \mathrm{m}^{2}$.

Usually, the dielectric properties of polymers are thickness-dependent. For instance, it is well known for many years that the dielectric strength presents a reciprocal thickness dependence given by ${ }^{22}$

$$
F_{B} \sim d^{-n}
$$

where $F_{B}$ is the breakdown field, $d$ is the material thickness, and $n$ is a constant. It has long been reported that the $n$ parameter reaches values between 0.24 and 0.65 in various kinds of aromatic polymers for material thicknesses $>8 \mu \mathrm{m} .^{23}$ Recently, lower values between 0.16 and 0.24 have been identified in thinner aromatic polyimide films $<8 \mu \mathrm{m} .{ }^{16}$ However, larger values $(1 \leq n \leq 1.5)$ have been reported in PTFE thin semicrystalline films. ${ }^{10}$ With such a large range of values found in the literature, it appears as quite difficult to relate $n$ with a particular breakdown mechanism.

In the present study, the dielectric strength has been characterized in a large thickness range (2 decades) in order to understand the impact of PA-HT film morphology and microstructure on the breakdown field. Fig. 6 shows the thickness dependence of the DC dielectric strength in

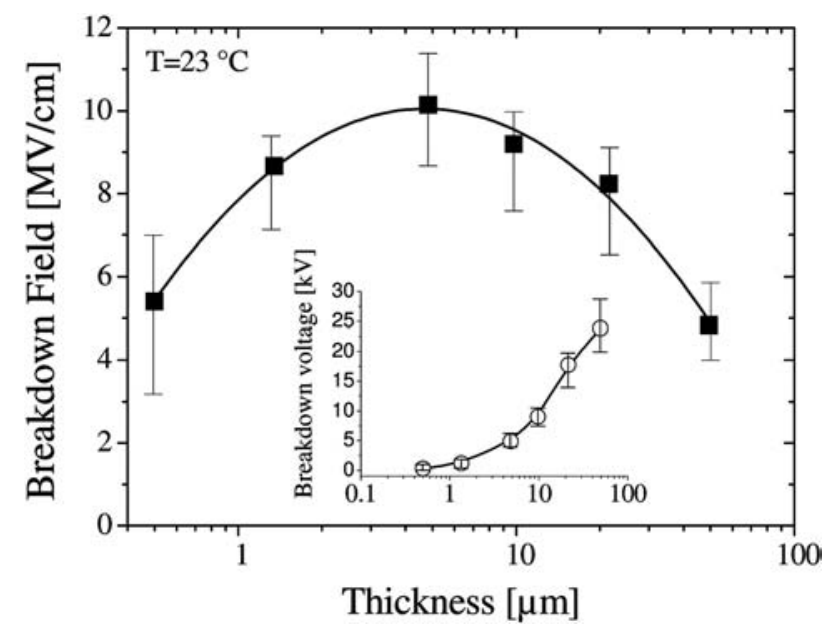

FIG. 6. Thickness-dependence of the DC dielectric strength for PA-HT films. The inset figure corresponds to the measured DC breakdown voltage versus thickness. Error bars show the minimum and maximum values obtained during the experimental tests.
PA-HT film between $500 \mathrm{~nm}$ up to $49.4 \mu \mathrm{m}$. The dielectric strength exhibits two different behaviors. For thicknesses above $4.8 \mu \mathrm{m}$, the breakdown field decreases, as expected, and a value of $n=0.4$ has been derived in good agreement with other values found in the literature. On the contrary, for thicknesses lower than $4.8 \mu \mathrm{m}$, a peculiar and substantial increase in the breakdown field is obtained with increasing thickness. In this region, the dielectric strength can be described by the following empiric law:

$$
\left.F_{B}\right|_{d<d_{C}} \sim d^{n}
$$

In this range, the value of $n$ is 0.3 and the breakdown field strongly increases by almost a factor 2 from 5.4 to 10.1 $\mathrm{MV} / \mathrm{cm}$. Such a behavior for thin films has never been reported up to now. The dielectric strength reaches its maximum value for an optimal thickness $\left(d_{\text {optim }}\right)$ around $5 \mu \mathrm{m}$.

In the present study, the value of the optimal thickness $d_{\text {optim }}$ corresponding to the dielectric strength maximum is slightly below the critical thickness $d_{C}$ for which spherulites appear in PA-HT films. Some interpretations of the electrical observations can be carried out considering all the experimental results.

It is well known that spherulites are made up of both crystalline and amorphous phases. The edges of spherulites are usually constituted of an amorphous phase. In such amorphous phase, electronic charges are strongly mobile and are able to receive a great amount of energy (due to large mean free path in free volume) to be accelerated along large distances within the bulk. ${ }^{22}$ If the charges receive a sufficient amount of energy, they can cause successive ionizations leading to additional charge release within the bulk. The charge multiplication progressively runs the material to the electronic avalanche. In addition, for high thicknesses $d \gg d_{C}$, the spherulite growing and multiplication lead to accelerate the breakdown process due to an increase in the probability of formation of boundaries between distinct spherulites. These boundaries (totally amorphous) can easily favour the occurrence of an electronic path leading to the breakdown. Consequently, the fact that the dielectric strength is degraded from $d \geq d_{C}$ can be related to the development and the multiplication of spherulites within the PA-HT films (micro-scale structural effects).

For the thinnest films $\left(d<d_{C}\right)$, the thickness-dependence of the dielectric strength is totally different and on the contrary it is improved $\left(F_{B} \sim d^{0.3}\right)$. In this case, spherulites are not able to develop due to the volume confinement (i.e., thickness limitation). When the confinement is progressively relaxed, the crystallinity is increased with increasing the thickness up to $d_{\text {optim }}$ and the macromolecular chains can be organized in the form of lamellae stacks with crystallite growth. Thus, as the amorphous phase is decreased within the bulk, local acceleration of free charges becomes more difficult and higher electric field are necessary to reach the dielectric breakdown. Therefore, for $d \ll d_{C}$, the dielectric strength is mainly controlled by nano-scale structural effects like the crystallite size. Moreover in this case, the $n$ value of the positive thickness-dependence of $F_{B} \sim d^{0.3}$ is in close relation with the crystallization enhancement at the nano-scale. 
In the case of $d \sim d_{\text {optim }}$, PA-HT films benefit of both a high crystallite size and the absence of spherulites in the bulk. Consequently, the dielectric breakdown field appears as maximal for this thickness. Fig. 7 summarizes the above explanations by presenting a model of spherulite development in PA-HT films as a function of increasing the thickness.

As reported previously, the PA-HT crystallite size is very sensitive to the temperature, particularly when the material is exposed at temperature above the crystalline transition $T_{c} \sim 385^{\circ} \mathrm{C} .{ }^{14,15}$ Indeed, it was shown that an exposition of PA-HT films $(d \sim 10 \mu \mathrm{m})$ during few minutes at a high temperature of $400{ }^{\circ} \mathrm{C}$ allows a growth of the crystallites from $\sim 5 \mathrm{~nm}$ up to $7.8 \mathrm{~nm}$ with a simultaneous spherulite development up to $10 \mu \mathrm{m}$ in diameter. ${ }^{14,15}$ The effects of such an annealing on the dielectric and electrical properties at low electric fields were studied. It was observed that both the DC conductivity (due to mobile charge carriers) and the permittivity and dielectric losses (due to local and segmental dipole relaxation) were reduced substantially. These observations were related to a decrease in the amorphous phase volume, wherein the charges and dipoles dynamics is higher than in the crystalline phase.

In the present case, and after the same annealing, no thickness dependence of the crystallite size was observed and a unique value of $7.8 \mathrm{~nm}$ has been derived using Eq. (1). Table I presents the changes in the breakdown field between as-deposited (or uncured) and $400{ }^{\circ} \mathrm{C}$-annealed PA-HT films for different thicknesses.

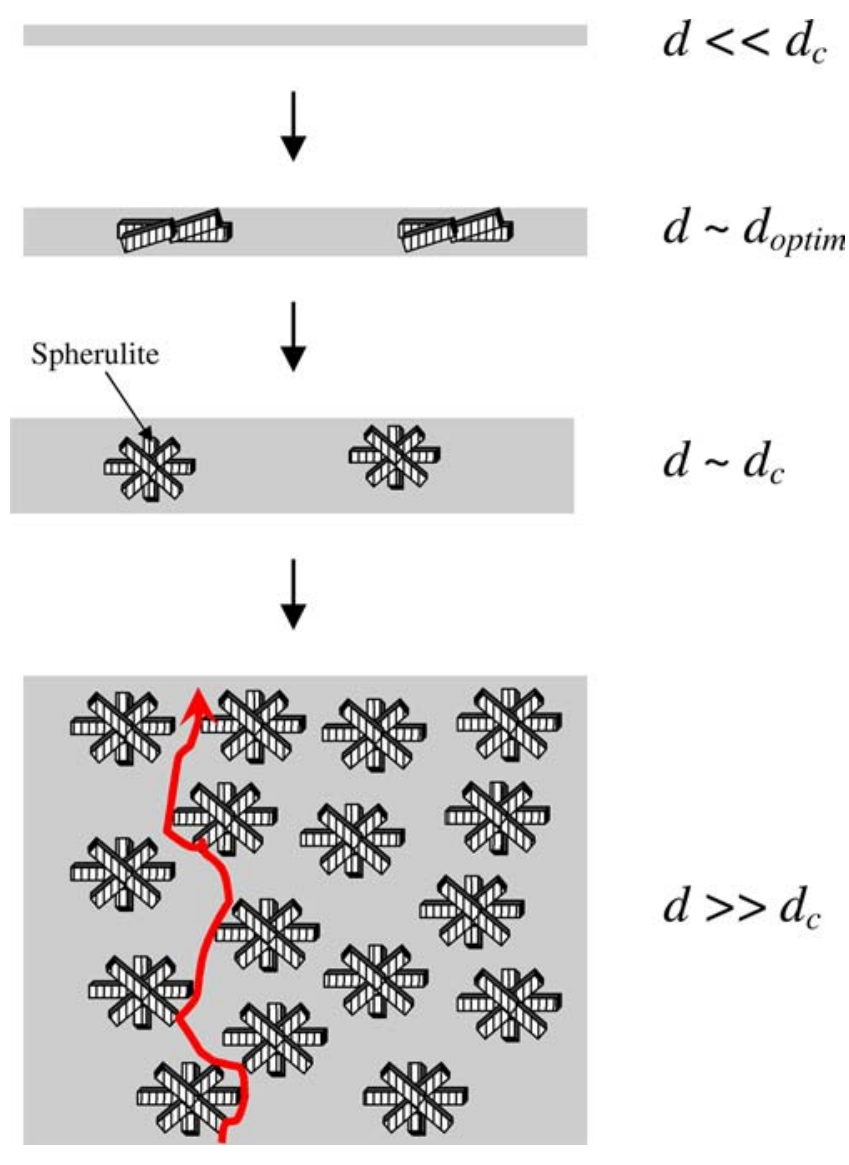

FIG. 7. Model of spherulites development in PA-HT films as a function of thickness. The curved arrow corresponds to a breakdown path via amorphous phase along spherulite boundaries.
TABLE I. Effect of a $400{ }^{\circ} \mathrm{C}$-annealing on the dielectric strength for different thicknesses.

\begin{tabular}{lccc}
\hline \hline & \multicolumn{3}{c}{$F_{B}(\mathrm{MV} / \mathrm{cm})$} \\
\cline { 2 - 4 } & $d=1.4 \mu \mathrm{m}$ & $d=4.8 \mu \mathrm{m}$ & $d=49.4 \mu \mathrm{m}$ \\
\hline As-deposited films & 8.7 & 10.1 & 4.8 \\
Annealed films & 10.0 & 10.6 & 6.2 \\
\hline \hline
\end{tabular}

Whatever the thickness, the dielectric strength exhibits an increase after the film annealing. The enhanced breakdown field is in good agreement with the other low field properties reported elsewhere. ${ }^{14,15}$ After the annealing, it is observed that the critical thickness $d_{C}$ remains unchanged and no spherulite was observed for $d<d_{C}$, while the mean spherulites diameter is increased by a factor $2(\sim 10 \mu \mathrm{m})$. The enhancement of the breakdown field induced by the annealing can be explained by an additional reduction of the amorphous phase (i.e., crystallite size growth) and, consequently, by the mobile charges density and/or their mobility decrease. Moreover, $F_{B}$ appears as almost thicknessindependent for $d<d_{C}$. In this range, the dielectric strength remains only controlled by nano-scale structural parameters such as the crystallite size and/or the interlamellar spacing.

For higher thicknesses $\left(d \geq d_{C}\right)$, the dielectric strength is also increased compared to as-deposited films but remain lower than that of low thickness. In addition, the annealing induces both the growth of the crystallites and spherulite diameter. ${ }^{14}$ This leads to highlight that in this thickness range, both nano-scale (due to crystallites) and micro-scale (due to spherulites) effects appear as key structural parameters to explain the very high field properties.

\section{CONCLUSION}

The dielectric strength of parylene HT (PA-HT) films deposited by vapor deposition polymerization has been investigated at room temperature in a wide thickness range from $500 \mathrm{~nm}$ to $50 \mu \mathrm{m}$. Correlations of the electrical results with nano- and microstructure analyses are reported. Two distinct behaviors of the dielectric strength have been identified in the investigated thickness range. From $\sim 10 \mu \mathrm{m}$ in thickness, PA-HT films exhibit an expected decrease of the breakdown field following a negative slope $\left(F_{B} \sim d^{-0.4}\right)$, while below this value, the dielectric strength increases with increasing the thickness $\left(F_{B} \sim d^{0.3}\right)$. An optimal thickness $\left(d_{\text {optim }}\right)$ corresponding to an extremum dielectric strength is obtained around $\sim 5 \mu \mathrm{m}$. X-ray diffraction has shown that PA-HT film crystallization is enhanced with increasing the thickness and that a continuous increase in the crystallite size is occurring. Simultaneously, polarized optical microscope observations have revealed that from a critical thickness $\left(5 \mu \mathrm{m}<d_{C}<10 \mu \mathrm{m}\right)$, a spherulite microstructural organization of the macromolecular chains appears within PA-HT films and is developed as the thickness increases. A model of spherulite development in PA-HT films with increasing the thickness is proposed. For $d \geq d_{C}$, the dielectric strength degradation is explained by the progressive 
spherulites development where charge carriers can be accelerated along large distances in the amorphous phase at the spherulite boundaries until inducing the breakdown. For $d<d_{C}$, the dielectric strength decreases with decreasing the thickness and the electrical properties are controlled only by nano-scale structural parameters (crystallite size). Finally, the effect of an annealing of the PA-HT films has been studied showing a higher dielectric strength compared to as-deposited ones. Under such conditions, the breakdown strength shows a nano-scale structural dependence for $d<d_{C}$ and both nano- and micro-scale structural influences for $d \geq d_{C}$. The understanding of these physical properties evolution should allow an optimized design of the electrical insulation system for high voltage power electronic devices.

\section{ACKNOWLEDGMENTS}

The authors warmly thank the financial support brought to this work by the General Directorate of Armaments of the French Ministry of Defense (DGA) and the General Directorate of Competiveness, Industry, and Services of the French Ministry of Productive Recovery (DGCIS). The authors are also very grateful to Speciality Coating Systems, Inc. (SCS) for supplying the parylene HT films.

${ }^{1}$ W. R. Dolbier, Jr. and W. F. Beach, J. Fluorine Chem. 122, 97 (2003).

${ }^{2}$ R. Kumar, D. Molin, L. Young, and F. Ke, in Proceedings of the Applied Power Electronics Conference and Exposition (IEEE, 2004), Vol. 2, p. 1247.
${ }^{3}$ W. F. Beach, C. Lee, D. R. Bassett, T. M. Austin, and R. Olson, "Xylylene polymers," in Encyclopedia of Polymer Science and Engineering, 2nd ed. (John Wiley \& Sons, New York, 1991), Vol. 17, p. 990.

${ }^{4}$ K. Fukao, S. Uno, Y. Miyamoto, A. Hoshino, and H. Miyaji, Phys. Rev. E 64, 051807 (2001).

${ }^{5}$ R. D. Priestley, L. J. Broadbelt, J. M. Torkelson, and K. Fukao, Phys. Rev. E 75, 061806 (2007).

${ }^{6}$ Y. Wang, S. Ge, M. Rafailovich, J. Sokolov, Y. Zou, H. Ade, J. Lüning, A. Lustiger, and G. Maron, Macromolecules 37, 3319 (2004).

${ }^{7}$ C. Qiao, S. Jiang, X. Ji, L. An, and B. Jiang, Front. Chem. China 2, 343 (2007).

${ }^{8}$ C. Lai, R. Ayyer, A. Hiltner, and E. Baer, Polymer 51, 1820 (2010).

${ }^{9}$ J. Liu, X. Qiao, S. He, Q. Cao, and H. Wang, J. Appl. Polym. Sci. 115, 1616 (2010).

${ }^{10}$ H. K. Kim and F. G. Shi, IEEE Trans. Dielectr. Electr. Insul. 8, 248 (2001).

${ }^{11}$ K. Kitagawa, G. Sawa, and M. Ieda, Jpn. J. Appl. Phys., Part 1 20, 87 (1981).

${ }^{12}$ L. E. Amborski, J. Polym. Sci. 62, 331 (1962).

${ }^{13}$ K. Ikezaki, T. Kaneko, and T. Sakakibara, Jpn. J. Appl. Phys., Part 120 609 (1981).

${ }^{14}$ S. Diaham, M. Bechara, M.-L. Locatelli, and C. Tenailleau, J. Electron. Mater. 40, 295 (2011)

${ }^{15}$ S. Diaham, M. Bechara, M.-L. Locatelli, and T. Lebey, J. Appl. Phys. 110, 063703 (2011)

${ }^{16}$ S. Diaham, S. Zelmat, M.-L. Locatelli, S. Dinculescu, M. Decup, and T. Lebey, IEEE Trans. Dielectr. Electr. Insul. 17, 18 (2010).

${ }^{17}$ M. Morgen, S. H. Rhee, J. H. Zhao, I. Malik, T. Ryan, H. M. Ho, M. A. Plano, and P. Ho, Macromolecules 32, 7555 (1999).

${ }^{18}$ J. J. Senkevich, J. Vac. Sci. Technol., A 18, 2586 (2000).

${ }^{19}$ A. Kahouli, J. Appl. Phys. 112, 064103 (2012).

${ }^{20}$ A. L. Patterson, Phys. Rev. 56, 978 (1939)

${ }^{21}$ G. R. Strobl, The Physics of Polymers (Springer, Berlin, 1996).

${ }^{22}$ R. Bartnikas and R. M. Eichhorn, Engineering Dielectrics, Volume IIAElectrical Properties of Solid Insulating Materials: Molecular Structure and Electrical Behavior (ASTM-STP 783, Philadelphia, 1983).

${ }^{23}$ B. Helgee and P. Bjellheim, IEEE Trans. Electr. Insul. 26, 1147 (1991). 